\title{
RISO E REGENERAÇÃO: O MEDIEVO DO SÉCULO XIV ATRAVÉS DO ESCRITO LITERÁRIO DE GIOVANNI BOCCACCIO
}

\section{LAUGH AND REGENERATION: THE MEDIEVAL OF THE XIV CENTURY THROUGH THE LITERARY WRITEN OF GIO- VANNI BOCCACCIO}

Amanda Cristina Zattera ${ }^{1}$

Resumo: No presente artigo realizamos uma análise sobre uma importante obra literária do período tardo-medieval: Decamerão de Giovanni Boccaccio (1313-1375). Escrita na Florença do século XIV, ela apresenta, no teor de suas narrativas, resquícios de um contexto marcado pela ideia da Morte, tendo em vista as terríveis circunstâncias e consequências nefastas que a Peste Negra, desde 1347, havia trazido para a região europeia. Propomos então observar o otimismo e o riso como uma das formas de agir perante uma realidade de cotidianidade da morte.

Palavras-Chave: Giovanni Boccaccio; Peste Negra; Crise; Riso.

Abstract: In this article we presents an analysis of an important literary work of the late medieval period: The Decameron by Giovanni Boccaccio (1313-1375). Writen in Florence of the fourteenth century, it shows, in the content of their narratives, remnants of a context marked by the idea of death, in view of the dire circumstances and terrible consequences that the Black Death, from 1347, had brought to the european region. We propose to observe the optimism and laughter as an way to act towards a reality of daily life from death.

Key Words: Giovanni Boccaccio, Black Death, Crisis, Laugh.

${ }^{1}$ Graduanda em História pela Universidade Federal do Paraná, sob orientação da Professora Doutora Marcella Lopes Guimarães. 
O recurso às fontes literárias é uma prática cada vez mais frequente no plano de investigação do passado realizado pelos historiadores da atualidade. De fato, presenciamos um afluxo crescente de estudos que propõem observar possíveis indícios de uma realidade mimetizada na literatura. Seguindo este pressuposto, o presente artigo contempla um estudo sobre o período tardo-medieval, tendo por base algumas percepções de análise sobre uma obra literária composta à época: Decamerão de Giovanni Boccaccio, escrita em Florença entre 1349 e 1351, esta obra apresenta, no teor de suas narrativas, elementos de um contexto marcado pela ideia da Morte, tendo em vista as terríveis circunstâncias e consequências nefastas que a Peste Negra, desde 1347, havia trazido para a região europeia. Propomos então, a partir da análise de algumas das novelas que compõem a obra, observar a presença do riso e do otimismo como uma possível reação da sociedade diante de um momento de provações, uma alternativa de fuga para aqueles que optaram por aproveitar a vida em um período de incertezas.

Os personagens da obra do florentino Giovanni Boccaccio (13131375), são três rapazes (Pânfilo, Filóstrato e Dionéio) e sete moças (Pampinéia, Filomena, Neífile, Fiammetta, Elisa, Laurinha, Emília), os quais fogem do caos da Peste Negra citadina em direção de um castelo no campo. Lá, com o fim de se entreterem, a cada um dos jovens é proposto que se conte uma jornada de dez novelas, conduzindo como reis ou rainhas suas narrativas, ao longo de dez dias, totalizando as cem novelas que compõem o Decamerão. De antemão, constatamos a 
menção à real fuga das pessoas que buscavam meios de salvação em um contexto de presença constante da morte.

Boccaccio escreveu sua mais famosa obra, refugiado provavelmente em Nápoles. A fuga para outros locais era uma prática recorrente para enfrentar as dificuldades, era a principal atitude diante do cataclismo; principalmente no período de peste, buscava-se o refúgio longe das cidades populosas, na zona rural, com população dispersa. É assim que nos é relatado, através da primeira das dez jornadas do Decamerão, as pessoas abandonavam o lugar onde se encontravam, antes que as pestilências ali surgissem, pois a cólera divina era associada também ao local, à cidade abatida. Segundo Boccaccio:

\begin{abstract}
Afirmo, portanto, que tínhamos atingido já o ano bem farto da Encarnação do Filho de Deus, de 1348, quando na mui excelsa cidade de Florença, cuja beleza supera a de qualquer outra da Itália, sobreveio a mortífera pestilência. Por iniciativa dos corpos superiores, ou em razão de nossas iniquidades, a peste atirada sobre os homens por justa cólera divina e para nossa exemplificação, tivera início nas regiões orientais, há alguns anos. Tal praga ceifara naquelas plagas, uma enorme quantidade de pessoas vivas (BOCCACCIO, 1996: 16).
\end{abstract}

Esse momento acarretou uma grande transformação dos Estados, das estruturas sociais e econômicas, assim como das mentalidades, pois segundo Georges Duby, quando um terço ou metade da população desaparece subitamente, são gigantescas as consequências sociais e psicológicas (DUBY, 1996: 86). As catástrofes que ocorreram no tardomedievo estavam associadas, devido às visões dos homens e mulheres do período, à imagem dos três cavaleiros do apocalipse: a fome, a guerra 
e a epidemia. Nenhum desses fenômenos era desconhecido das fases precedentes da Idade Média, mas tanto sua intensidade como certos aspectos novos, criavam uma impressão inaudita (LE GOFF, 2007: 220221).

Esse período, considerado por Johan Huizinga como um momento de continuidades e mudanças, é também visto pelo autor como um período de cores turvas, o próprio título do Outono da Idade Média sugere um momento soturno, e a partir desses aspectos evidencia em sua obra as formas de vida e pensamento do final da medievalidade. De fato, como nos ressalta Huizinga, os homens do Baixo Medievo enfrentaram a fome e as dívidas (HUIZINGA, 2010: 78), porém, ressaltamos que essa crise já havia dado mostras em tempos enaltecidos e o que parecia ser o anúncio de uma depressão, nos suscita vários questionamentos acerca das reações da sociedade diante dessas situações, que eram derivadas de uma gama de acontecimentos ocorridos desde meados do século XIII.

As pessoas do período encontraram espaço para a liberação dos acontecimentos difíceis a que estavam sujeitas, não sendo o desespero e o pessimismo, as únicas formas de enfrentar uma realidade tão complexa. Nesse contexto onde morte e renovação eram então inseparáveis, as experiências e o modo de pensamento dos homens e mulheres do período, que viveram também essas experiências ambivalentes, influenciaram a literatura, as artes visuais, as formas representativas em geral. Pois, apesar das provações, não havia espaço apenas para a tristeza e o pessimismo, pois se a guerra, a fome e a peste 
eram parte do cotidiano, a vida seguia afinal para aqueles que ainda podiam aproveitá-la, e nessa realidade tão ambivalente, a vida era valorizada, e o medo tão presente, era liberado muitas vezes através do cômico, e do riso que se apresenta como a própria essência da obra de Boccaccio, uma alternativa apresentada ao público contemporâneo ao autor, e que se estendeu à posteridade.

Essa perspectiva de luta pela vida, em uma época marcada pela presença inevitável da morte, está presente no Decamerão, que através de sua narrativa bem humorada, apresenta-se aos seus leitores, como uma das alternativas de alegria perante o momento difícil:

Como a dor se localiza ao estremo oposto àquele em que se acha a alegria, fica evidenciado que os sofrimentos terminam quando se inicia a satisfação superveniente. A este breve desgosto - digo breve porque pode ficar restrito a poucas palavras - se seguem com toda solicitude, a doçura e o prazer (BOCCACCIO, 1996: 20).

A perspectiva do riso em um momento de presença constante da morte é observada em grande parte das novelas do Decamerão. A primeira narrativa, feita por Pânfilo, conta a história do Senhor Ciappelletto, um homem descrito como materialista, que fazia documentos falsos, além de dar falso testemunho, e de gozar extraordinário prazer em causar discórdias e escândalos entre amigos e parentes. Senhor Ciappelletto havia também ferido e matado homens com as próprias mãos, sendo um blasfemador de Deus e dos santos. Esse homem foi solicitado por um rico comerciante, chamado Musciatto 
Franzesi, para receber dos borgonheses que lhe deviam. Como na Borgonha ninguém o conhecia, agia com bondade, contrariando o próprio temperamento.

Ficando hospedado na casa de dois irmãos florentinos, o Senhor Ciappelletto adoeceu, “(...) parecia ter, no corpo, o mal da morte" (BOCCACCIO, 1996: 36). Após ouvir uma conversa dos irmãos sobre a preocupação que tinham, pois não poderiam abandoná-lo doente e já conhecendo sua verdadeira índole sabiam que não poderia confessar-se e portanto, não receberia nenhum sacramento, não havendo igreja que aceitasse seu corpo caso falecesse, o Senhor Ciappelletto executa um plano para resolver o problema dos irmãos.

Ao mandar vir um frade valoroso, o doente faz sua confissão, contando para esse frade, inúmeras mentiras, afirmando ser virgem e confessar-se todas as semanas, além de condenar tabernas. $\mathrm{O}$ frade pensando estar diante de um cristão tão honrado, prometeu-lhe, caso viesse a falecer, seria enterrado em um lugar sagrado. Os dois irmãos, “(...) algumas vezes sentiam tanta vontade de rir, ao escutarem o que ele confessava ter feito, que quase explodiam" (BOCCACCIO, 1996: 43). Ao cair da noite daquele mesmo dia o Senhor Ciappelletto morreu.

$\mathrm{O}$ frade que o havia confessado, acreditando que seu confessor era um homem santo, e que através dele, Deus faria muitos milagres. Com polpa e solenidade o corpo foi levado para a igreja, e após seu sepultamento, o povo pôs-se a visitar sua sepultura, e assim a fama de santidade do homem foi aumentando, passando a ser chamado de São Ciappelletto. 
É importante ressaltarmos, a partir da análise dessa novela, uma das formas de agir que Boccaccio nos apresenta, não sendo a proximidade da morte motivo de lamentação para o personagem, mas de uma atitude que acaba por tornar-se, de certa forma, cômica. Esse estilo de narrativa crítica e repleta de sarcasmo social é uma via de interpretação do autor acerca do comportamento social de sua própria realidade, o ambiente italiano do século XIV.

Esse sentimento otimista é constante ao longo da Segunda Jornada, que tem como tema estabelecido, narrativas que falem de quem, perseguido por incontáveis contratempos, alcançou um fim tão feliz, que superou as suas esperanças. De fato, a busca por algo desejado e a não desistência diante dos infortúnios indicam uma postura otimista em um contexto repleto de dificuldades. São homens e mulheres que, de maneira semelhante, através da superação e com ajuda da Sorte, conquistam a Felicidade através da fuga de uma triste realidade e da busca por aquilo que desejavam.

Assim ocorreu com Martellino, na primeira novela narrada por Neífile. Martellino chegou em Treviso juntamente com dois amigos, Stecchio e Marchese, praticantes de diversas imitações. Em um determinado momento os três, verificando a grande quantidade de pessoas que se reuniam na igreja local, tomaram conhecimento de que se velava o corpo de um bondoso homem que falecera a pouco tempo, chamado Arrigo. Este estava sendo considerado como santo, pois na hora de sua morte os sinos da maior igreja começaram a tocar sem que ninguém o fizesse. Nesse instante os amigos, desejosos de se 
aproximarem do corpo, foram movidos pela seguinte idéia de Martellino: este se fingiria de aleijado para, assim, amparado por seus amigos, se aproximar do corpo; no momento que chegasse perto, porém, ele voltaria ao normal, fingindo-se curado.

Desmascarado por um florentino que o conhecia, acabou salvo graças aos dois amigos, que o acusaram de roubo para que fosse levado pelas autoridades, e posteriormente intercederam junto a um homem que tinha prestígio com o juiz. Este narrou tudo ao senhor da cidade, que achou graça do fato. Assim, cada um dos três amigos, após ganhar um novo traje, voltou para sua respectiva casa. Semelhante sorte encontrou o mercador Rinaldo d'Asti, personagem principal do relato de Filóstrato, na segunda novela. Em uma viagem de negócios, Rinaldo d'Asti acabou sendo assaltado por ladrões, e sem seus pertences, abrigou-se na casa de uma bela viúva, que vivia nas proximidades de um castelo, devido ao seu amor com o marquês Azzo. Ceiou, banhou-se e passou a noite em companhia da mulher, que estava só naquela noite. Ao amanhecer descobriu que, por milagre, os assaltantes haviam sido presos por outro crime, conseguindo assim recuperar seu cavalo e seus pertences. Com a sorte dada por Deus e por São Juliano, por quem o mercador mantinha devoção, Rinaldo então retornou a sua casa. Dessa forma, através da esperteza ou da ajuda da Sorte, seria sempre possível reverter uma situação desagradável.

Já na terceira novela, narrada por Pampinéia, os três personagens (Lamberto, Tebaldo e Agolante) chamam o sobrinho deles, Alexandre, para cuidar dos negócios florentinos na Inglaterra. Quando as despesas 
se tornam gigantescas para os tios, Alexandre teve de sair da Inglaterra e voltar para Florença. Ao deixar Bruges percebeu que também partia de lá um abade branco seguido de muitos monges e dois cavaleiros idosos, parentes do rei. Esses últimos ficaram amigos de Alexandre durante a viagem e o jovem tornou-se também amigo do abade branco. No entanto, descobrimos que o "abade branco" era na verdade um disfarce: tratava-se na verdade da filha do rei da Inglaterra. Assim a filha do rei da Inglaterra, que se dirigia até Roma para alcançar matrimônio por meio do papa, no caminho da viagem conhece Alexandre e acaba cumprindo os votos de matrimônio com este jovem. A esposa então impõe que fossem soltos os tios de Alexandre que estavam presos por dívidas. E segundo Boccaccio:

Feito isto, Alexandre e sua mulher, levando com eles Agolante, saíram de Florença, dirigindo-se a Paris, onde o rei os recebeu, sempre com magnificência. Mais tarde, os dois cavaleiros voltaram à Inglaterra; e tanto insistiram junto ao rei que, por fim, este deu seu perdão; recebeu a filha, de volta, e o genro, igualmente, com brilhantes festejos. Passado algum tempo, elevou o genro à dignidade de cavaleiro, numa cerimônia magnífica; e concedeu-lhe o Condado de Cornualha. Soube Alexandre resolver de tal maneira todos os assuntos, que acabou promovendo a paz entre pai e filho (BOCCACCIO, 1996: 86).

Agolante conseguiu recuperar a riqueza dos irmãos, voltou rico para Florença e "antes de partir, o conde Alexandre fê-lo cavaleiro. O conde, depois disso, viveu gloriosamente com sua esposa. Querem alguns certificar que ele, combinando o seu natural bom senso e o valor com o auxílio do sogro, tenha conquistado a Escócia, coroando-se seu 
rei” (BOCCACCIO, 1996:86). Nessa novela de Boccaccio a mudança de grupo social por Alexandre recebe atenção e os estereótipos estão vinculados às presenças da nobreza, dos gentis-homens, dos monges, do papa e das ações dos mercadores-banqueiros. De acordo com Eric Auerbach, Boccaccio examina e descreve de maneira mais concreta todas as camadas sociais, todos os ofícios e as classes do seu tempo. "O Decamerão fixa pela primeira vez, após a antiguidade, certo nível estilístico, dentro do qual a narração de acontecimentos reais da vida presente se pode converter numa discussão culta" (AUERBACH, 2009: 181).

Esse modo de representação dos fatos, realizado Boccaccio, alude por meio da literatura, aos fatores filosóficos e históricos da época do autor: um ambiente em que a Peste Negra foi uma caçadora de sorrisos, e que, conforme podemos constatar nas novelas do Decamerão, a sociedade lentamente aprende a respirar, a sorrir e ressurgir. Segundo Guimarães, “importa perceber, então, que a literatura, sem espelhar o real, nasce de uma prática sem a qual a sua representação não seria compreendida, e apresenta uma maneira de lidar com a realidade muitas vezes lúgubre mas sem abrir mão da edificação, da fruição e da graça (GUIMARÂES, 2010: 123).

Perspectiva presente também na próxima novela, narrada por Elisa, que relata a aparente má sorte de Válter, conde da Antuérpia. No conto, Válter ficou responsável pelo reino da França, enquanto o rei e seu filho estavam na guerra. Amado pela esposa do filho do rei, acabou sendo acusado por ela de tê-la agarrado a força, em atitude de vingança 
por um amor não correspondido. Válter, que era viúvo e tinha dois filhos pequenos, fugiu para Londres, onde deixou a filha com uma dama e o filho com o mordomo do rei. Partiu, logo após, para viver na Irlanda, onde trabalhava muito.

Muito tempo se passou até que ele foi em busca de seus filhos: encontrou a filha casada, fruto de um romance com o filho da dama que a criou; o filho, que também havia casado, havia entretanto perdido grande parte de sua família devido a peste, tornando-se depois mordomo. Segundo Boccaccio: "Ocorreu naquela parte da Inglaterra, uma pestilenta mortandade, que ceifou quase metade dos habitantes, não é necessário dizer-se que grande parte dos que sobreviveram se refugiou, com medo, em outras regiões" (BOCCACCIO, 1996: 110).

Feliz pela boa sorte dos filhos, Válter logo foi perdoado, sendo restituído de seu título e de todos os seus bens após a confissão da nora do rei, que finalmente contou a verdade em seu leito de morte. O conde viveu gloriosamente em Paris até seus últimos dias. Percebemos que a sorte perante momentos de dificuldades, como a peste negra, e o encontro da felicidade após tantos infortúnios, são presença constante na narrativa do erudito medieval, conforme observamos ocorrer com os personagens Rinaldo, Alexandre e Válter, nas novelas analisadas. Essa perspectiva nos possibilita uma reflexão acerca das diversas possibilidades de agir diante de momentos de provação.

Ao estabelecer um diálogo com a obra de Huizinga, Wolff afirma que o outono certamente é a aproximação do inverno, mas também são tão belos os frutos que nele se colhem. O autor ressalta que os choques 
das crises desse período não foi apenas material, os espíritos foram atingidos. Wolff não nega as tantas dificuldades que fizeram com que o período fosse considerado por muitos autores como um momento de decadência, mas ressalta que as dificuldades e provações aconteceram em diversos momentos da história (WOLFF, 1988: 09).

Vem nesse sentido o relato (presente na quarta novela) de Laurinha acerca de Landolfo Ruffolo, rico homem de Ravelo, pequena cidade italiana, que não contente com sua riqueza resolveu arriscar-se e lançar-se no comércio marítimo. Sem a sorte esperada acabou perdendo tudo o que tinha, tornando então pirata. Acabou tendo nessa atividade mais sorte que na anterior, multiplicando seus bens. Porém, genoveses roubaram tudo o que Landolfo havia conseguido e o levaram como prisioneiro em um navio, o qual acabou naufragando. $\mathrm{O}$ prisioneiro, no entanto, novamente teve sorte e salvou-se agarrado em uma caixa, sendo socorrido por uma mulher quando chegou até a praia. No momento em que verificou o conteúdo da caixa, descobriu uma boa quantidade de pedras preciosas. Vendeu-as, recompensou a senhora que o havia ajudado e voltou para sua cidade ainda mais rico do que quando saíra, pois encontrou a ajuda do Destino.

A astúcia feminina também se faz presente no ritmo de busca pela felicidade, como presenciamos na quinta novela. Nela, uma personagem siciliana interessada nos 500 florins de ouro carregados por um rapaz, de nome Andreuccio di Pietro, utilizou-se da ingenuidade dele para fingir ser sua irmã, para tal utilizando-se de informações obtidas através de uma senhora que o conhecia previamente. Levado até a casa da moça, 
esta lhe contou a mentira e o convenceu a jantar; quando, porém, foi utilizar o banheiro, ficou preso, momento em que a siciliana aproveitou a oportunidade para lhe roubar todo o dinheiro.

Ao perceber o que ocorrera, voltou para a cidade e encontrou dois rapazes a quem contou o ocorrido. Resolveu então fazer parte do plano dos dois, que haviam acabado de enterrar o corpo de um arcebispo e, naquele momento, percebido que ele usava um anel de rubi no valor de 500 florins. Andreuccio foi encarregado de entrar no túmulo e, se recusando a entregar o anel, lá foi trancado. Outros ladrões haviam tido a mesma idéia e se assuntaram ao encontrar um homem dentro do túmulo, fugindo e dando a possibilidade de Andreuccio sair de lá. Após momentos de lamentações por sua falta de sorte, com o anel ele acabou recuperando seus 500 florins de ouro.

Fortuna maior é aquela com que se deparou Arrighetto Capece, que reencontra após muito tempo toda sua família. Na sexta novela Emília relata os infortúnios, seguidos de muito esforço e boa sorte, de Arrighetto, que possuía boa condição no reinado de Manfredi da Sicília. No entanto, após este rei ser derrotado por Carlos I, Arrighetto acabou prisioneiro. Sua esposa, Berítola Caracciolo, deixou os bens com seu filho mais velho e partiu em fuga, grávida, em um barquinho com seus outros filhos. A mulher acabou isolada em uma ilha após um ataque de corsários e lá permaneceu sozinha, pois todos os outros haviam sido levados. Após algum tempo foi salva por uma embarcação: Conrado, o dono do navio, e sua esposa a levaram com eles. O filho mais velho de Berítola encontrou seu pai, que foi libertado após a morte de Carlos I. A 
família, enfim, viu-se novamente reunida com os outros filhos encontrados, e todos juntos então festaram. A fuga e a salvação como um ato coletivo são, como percebemos, característicos do período aqui tratado. O contraste entre a vida vazia de Berítola, enquanto estava sozinha, e a subseqüente festividade quando se reúnem demonstra que o sentimento de coletividade e proteção não abre espaço para individualidades.

Na obra de Boccaccio as mulheres também assumem uma postura muito confiante, pois são dotadas de garra e esperteza. Percebemos que a boa sorte, e o otimismo diante dos infortúnios, se fazem presentes para os mais diversos personagens, de diferentes camadas sociais, mesmo para aqueles de índole questionável, e ocorrem também das mais variadas maneiras, citamos como exemplo a boa sorte financeira, e a amorosa que se fazem presentes nas novelas.

A própria rainha Filomena, na referida nona novela, narra a história de Ambrosinho de Piacenza, que se utilizou do artifício da mentira unicamente com o fim de desafiar e provar para Barnabé, um genovês, a infidelidade de sua esposa. Na ocasião, Ambrosino, escondido, observou a dama e relatou detalhes do corpo dela para o marido, o qual acreditou na traição e ordenou a morte da esposa. No entanto esta conseguiu escapar e, vestida de homem, conquistou a confiança do sultão de Alexandria. Estando em Alexandria, Ambrosinho foi por ela descoberto e, trazendo o marido para o mesmo local, revelou sua identidade e como o mentiroso havia conseguido as ditas provas. 
Perdoado pela fiel esposa, Barnabé viveu com ela feliz, enquanto Ambrosinho teve uma triste morte, devorado pelos insetos. Essa possibilidade de mudar a própria sorte que observamos no caso de esposa de Barnabé encontra-se também na última novela. No conto, de acordo com Dionéio, vemos uma jovem, Bartolomeia, vivendo em profundo estado de melancolia, pois seu marido, um juiz chamado Ricardo de Quinzica, possuía e seguia um calendário que, devido aos diversos feriados e a quaresma, limitava o amor do casal. No entanto, em um dia de calor, durante uma pescaria, Bartolomeia foi seqüestrada por um corsário e passou a viver com ele um grande amor.

Quando encontrada pelo marido, afirmou que não era feliz com ele e que permaneceria com o corsário, pois ali não havia calendário que limitasse sua felicidade. Após algum tempo Ricardo faleceu e o corsário casou-se com ela, vivendo ambos uma vida feliz repleta de prazeres. Assim, a moça, não contente com seu destino, escolheu a sua própria sorte. Essa ideia de sorte presente no Decamerão esta relacionada as próprias atitudes e a maneira de agir perante as situações difíceis que fazem parte da vida, sendo a boa sorte, em muitas das narrativas, resultado de esforço e otimismo.

Esse conjunto de novelas deixa claro o sentimento e a consciência permanente de Boccaccio em relação à vida e suas possíveis armadilhas; ao mesmo tempo, porém, o autor aponta que, por meio da Razão e com uma influência do Amor, talvez consigamos sempre alcançar a seiva da vida, desfrutando-a. 
Essa liberação do medo através da alegria permeia toda a obra do erudito, pois as próprias narrativas das novelas são a maneira que os dez personagens principais encontram de viver com alegria enquanto estão fugindo da peste que já havia assolado grande parte das pessoas que eram por eles conhecidas.

Que o tema fosse recorrente ante o horror dos cadáveres putrefatos que a peste ou a guerra expunham é esperado, mas que o homem medieval encontrasse meios criativos de encarar a morte e fazê-la nova senhora de uma sociedade tão agarrada à hierarquia pode surpreender, e certamente oferece vieses outros de compreensão do período (GUIMARÂES, 2010: 123).

Podemos concluir, portanto, que crise e decadência não são sempre uniformes. As dificuldades pelas quais a Europa passou ao longo do século XIV não são negadas, pois são responsáveis por muitas mudanças que ocorreram nesse momento, mas analisar a Baixa Idade Média apenas pelo viés negativo da crise é fechar os olhos para a superação e prosperidade do período.

A ambiguidade do contexto se faz presente no Decamerão, pois as dificuldades se fazem presentes em grande parte das novelas que compõem a obra, mas a partir da análise do contexto e da narrativa de Boccaccio, pudemos perceber que na maior parte das histórias, quando há dificuldades, essas são seguidas por momentos de superação, de alegria, e do riso, frutos dos esforços, ou até mesmo da sorte dos personagens. 
Foi possível, portanto, observar a Baixa Idade Média italiana não como um prelúdio do humanismo e do Renascimento, mas como esse momento deu mostras de superação e prosperidade, essenciais para a regeneração da sociedade. Nesse sentido, nosso olhar observa e busca ressaltar a forte dinâmica característica desse período, parte de um longo e diverso medievo.

\section{Bibliografia}

AUERBACH, Eric. Frate Alberto. In: Mimesis: a representação da realidade na Literatura ocidental. Tradução coletiva para a língua portuguesa. São Paulo: Perspectiva, ed. 2009, pp. 177-201.

BOCCACCIO, Giovanni. Decamerão. São Paulo: Nova Cultural, 1996.

DUBY Georges. Ano 1000 ano 2000 na pista de nossos medos. São Paulo: Unesp, 1999.

GUIMARÃES, Marcella Lopes. "Cultura na Baixa Idade Média" in GIMENEZ, José Carlos (org.). História Medieval II: a Baixa Idade Média. Maringá: EDUEM, 2010.

HUIZINGA, Johan. O declínio da Idade Média. Lisboa: Ulisseia, 2006.

OLIVEIRA, Flávio Rodrigues de; OLIVEIRA, Terezinha de. A literatura e as transformações sociais na Baixa Idade Média: uma análise da obra $O$ Decamerão de Boccaccio. Anais da X Jornada de Estudos Antigos e Medievais da UEM. Maringá: UEM, 2011, pp.1-10.

LE GOFF, Jacques. A civilização do ocidente medieval. Tradução: José Rivair de Macedo. SP: EDUSC, 2005.

Vozes, 2007.pp . As raízes medievais da Europa. Petrópolis, RJ:

WOLFF, Philip. Outono da Idade Média ou Primavera dos Novos Tempos? São Paulo: Martins Fontes, 1988. 